\title{
Airport operations management
}

\author{
Jason Atkin ${ }^{1} \cdot$ Han Hoogeveen ${ }^{2} \cdot$ Raik Stolletz ${ }^{3}$ \\ Published online: 31 August 2019 \\ ๑) Springer-Verlag GmbH Germany, part of Springer Nature 2019
}

The airline industry is important for the global economy. Airports, in particular hub airports, are the backbone of air transportation. Operations in the terminal and at the airfield as well as the runways need to be planned in an efficient way. This special issue is dedicated to operations research methods supporting airport operations management. Large airports require a diversity of tasks to be performed and problems to be solved. Amongst them are resource allocation problems (e.g. gates/stands, check-in desks, baggage station or carousels); sequencing or scheduling problems (e.g. runway sequencing); timetabling and rostering problems (e.g. check-in or security staff); or routing problems (e.g. for aircraft). But many other problems can also be found in airports, such as facility location or passenger flow prediction and optimisation. Airports are key for the air transportation system, and inefficiencies there can have knockon effects throughout the air transportation system, delaying flights and potentially increasing pollutant emissions as well as costs.

Modern research trends are moving beyond the traditional static individual problems, considering multi-objective problems and trade-offs (e.g. fuel vs. cost vs. time), combined problems (e.g. runway sequencing and trajectory optimisation), dynamic and stochastic problems, creating more robust solutions, or considering some of the complex real-world constraints which can cause problems for the elegant solutions we may prefer. Perhaps unsurprisingly, this focus was observed in the research papers submitted for this special issue. From the 21 papers submitted to this special issue, the

$凶 \quad$ Raik Stolletz

stolletz@bwl.uni-mannheim.de

Jason Atkin

jason.atkin@nottingham.ac.uk

Han Hoogeveen

j.a.hoogeveen@uu.nl

1 School of Computer Science, University of Nottingham, Wollaton Road, Nottingham NG8 1BB, UK

2 Department for Information and Computing Sciences, Utrecht University, Princetonplein 5, De Uithof, 3584 CC Utrecht, The Netherlands

3 Chair of Production Management, University of Mannheim, 68131 Mannheim, Germany 
following three papers have been selected. All three contributions base their analysis on real-world data:

Dijk et al. (2019) consider the Tactical Stand Allocation problem (also known as the Gate Assignment problem) as it occurs at the Guarulhos International Airport of Sao Paulo. The quality of such a plan is judged on the basis of four conflicting objectives, one of which is maximising revenues. Moreover, the solutions must be robust to deal with deviations in the arrival and departure times. To solve this problem, the authors apply a variant of recoverable robustness to find a solution that can be made feasible for a set of scenarios generated on the basis of historical data.

Samà et al. (2019) consider a combined trajectory management and sequencing problem for aircraft landing and taking-off from an airport, aiming to improve a variety of performance indicators, illustrating the trade-offs within this combined problem, and considering the benefits of three different approaches to combining the problems. Computational experiments are performed on real-world data from Milano Malpensa airport.

Yalcin et al. (2019) analyse a grid-based storage system. They devise efficient algorithms to store new items or to retrieve stored items, where currently stored items can be pushed into other cells in the grid. Several variants of these strategies are tested in a simulation environment, which results are to be used to design a baggage storage system at Frankfurt Airport.

Our sincere thanks go to all of the authors and reviewers for contributing to this special issue.

\section{References}

Dijk B, Santos BF, Pita JP (2019) The recoverable robust stand allocation problem: a GRU airport case study. OR Spectr. https://doi.org/10.1007/s00291-018-0525-3

Samà M, D'Ariano A, Palagachev K, Gerdts M (2019) Integration methods for aircraft scheduling and trajectory optimization at a busy terminal manoeuvring area. OR Spectr. https://doi.org/10.1007/ s00291-019-00560-1

Yalcin A, Koberstein A, Schocke K-O (2019) Motion and layout planning in a grid-based early baggage storage system. OR Spectr. https://doi.org/10.1007/s00291-018-0545-z

Publisher's Note Springer Nature remains neutral with regard to jurisdictional claims in published maps and institutional affiliations. 